OPEN ACCESS

Edited by:

Senjie Lin,

University of Connecticut, USA

Reviewed by:

Hans Paerl,

The University of North Carolina at

Chapel Hill, USA

Hélène Montanié,

Université de la Rochelle, France

*Correspondence:

Petra M. Visser,

Department of Aquatic Microbiology, Institute for Biodiversity and Ecosystem Dynamics, University of

Amsterdam, PO Box 94248,

1090 GE Amsterdam, Netherlands p.m.visser@uva.nl

Specialty section: This article was submitted to

Aquatic Microbiology, a section of the journal Frontiers in Microbiology

Received: 10 April 2015 Accepted: 29 June 2015 Published: 22 July 2015

Citation:

Weenink EFJ, Luimstra VM, Schuurmans JM, Van Herk MJ, Visser

PM and Matthijs HCP (2015)

Combatting cyanobacteria with hydrogen peroxide: a laboratory study on the consequences for phytoplankton community and diversity. Front. Microbiol. 6:714. doi: 10.3389/fmicb.2015.00714

\section{Combatting cyanobacteria with hydrogen peroxide: a laboratory study on the consequences for phytoplankton community and diversity}

Erik F. J. Weenink ${ }^{1}$, Veerle M. Luimstra ${ }^{1,2}$, Jasper M. Schuurmans ${ }^{1,3}$, Maria J. Van Herk ${ }^{4}$, Petra M. Visser ${ }^{1 *}$ and Hans C. P. Matthijs ${ }^{1}$

${ }^{1}$ Department of Aquatic Microbiology, Institute for Biodiversity and Ecosystem Dynamics, University of Amsterdam, Amsterdam, Netherlands, ${ }^{2}$ Wetsus, Center of Excellence for Sustainable Water Technology, Leeuwarden, Netherlands, ${ }^{3}$ Department of Aquatic Ecology, Netherlands Institute of Ecology (NIOO-KNAW), Wageningen, Netherlands, ${ }^{4}$ Phytoplankton Expertise Center, Koeman en Bijkerk, Haren, Netherlands

Experiments with different phytoplankton densities in lake samples showed that a high biomass increases the rate of hydrogen peroxide (HP) degradation and decreases the effectiveness of HP in the selective suppression of dominant cyanobacteria. However, selective application of HP requires usage of low doses only, accordingly this defines the limits for use in lake mitigation. To acquire insight into the impact of HP on other phytoplankton species, we have followed the succession of three phytoplankton groups in lake samples that were treated with different concentrations of HP using a taxa-specific fluorescence emission test. This fast assay reports relatively well on coarse changes in the phytoplankton community; the measured data and the counts from microscopical analysis of the phytoplankton matched quite well. The test was used to pursue HP application in a Planktothrix agardhii-dominated lake sample and displayed a promising shift in the phytoplankton community in only a few weeks. From a low-diversity community, a change to a status with a significantly higher diversity and increased abundance of eukaryotic phytoplankton species was established. Experiments in which treated samples were re-inoculated with original $P$. agardhii-rich lake water demonstrated prolonged suppression of cyanobacteria, and displayed a remarkable stability of the newly developed post-HP treatment state of the phytoplankton community.

Keywords: biodiversity, harmful cyanobacteria, hydrogen peroxide, lake mitigation, phytoplankton (Planktothrix agardhii)

\section{Introduction}

In recent years the nuisance of harmful algae has increased rather than decreased (Stumpf et al., 2012; Michalak et al., 2013; Ai et al., 2015; Paerl et al., 2015), not only because of eutrophication; also climate change and rising carbon dioxide concentrations in the atmosphere make cyanobacteria thrive and contribute to their dominance (Paerl and Huisman, 2008; Carey et al., 2012;

Abbreviations: $\mathrm{HP}$, hydrogen peroxide, $\mathrm{H}_{2} \mathrm{O}_{2}$ 
Verspagen et al., 2014). Toxin-producing cyanobacteria pose a threat to water quality in freshwater systems on a worldwide scale. It is a global interest to have ecologically healthy lakes that supply sufficient clean fresh water for fisheries, irrigation, drinking water preparation, water-recreation and esthetical aspects of the visual and odor-wise appearance of surface waters. In water quality management, long-term prevention of cyanobacterial impact is a primary goal. The preferred remedy is restoration of a lake to its original pre-eutrophication state by means of nutrient reduction, but often this may take many years, or the required engineering efforts are regarded as impossible to implement in a particular local situation, or may prove too costly (Dodds et al., 2009). In invasive lake mitigation technology, diverse methods are available for the termination of harmful cyanobacterial blooms, but many are not selective, may leave traces of added chemicals behind, and often do not comply with the desirable selectivity to not overly damage lake-ecology. An example of the latter is the use of cyanocidal or cyanostatic agents like copper sulfate; conversely a range of extracted biological agents or unrefined products, such as barley or rice straw, has been used (for a review see Jancula and Marsalek, 2011). In lakes sufficiently isolated from surrounding water bodies that may otherwise supply the lake with nutrients, phosphate reduction methods like Flock-and-Lock can terminate the yearly phosphate cycle that caters the cyanobacterial dominance (Akhurst et al., 2004; Douglas et al., 2004; Conley et al., 2009; Lürling and Van Oosterhout, 2013; Lürling et al., 2014). Alternatively, artificial deep mixing (Visser et al., 1996; Huisman et al., 2004) and flushing (see Verspagen et al., 2006 and references therein) of lakes have been successfully applied in the reduction of cyanobacterial blooms.

A more recently developed fast and effective method makes use of a higher sensitivity of cyanobacteria to hydrogen peroxide, $\mathrm{H}_{2} \mathrm{O}_{2}$ (hereafter $\mathrm{HP}$ ), than other eukaryotic phytoplankton (Barroin and Feuillade, 1986; Drabkova et al., 2007a,b). The HPmethod for selective suppression of cyanobacteria has already proven beneficial for entire lake mitigation in our geographical temperate zone. Fast and effective intervention against the "bad" cyanobacteria in the phytoplankton accompanies the amelioration of "food chain-positive" phytoplankton taxa like green algae, diatoms and also zooplankton. In particular, the selectivity of the HP method is of interest for ecological water management. In 2009, a dense bloom of a Planktothrix agardhii (hereafter Planktothrix)-dominated recreational lake has been successfully treated with a pre-determined minimal final lake concentration of $2.3 \mathrm{mg} \cdot \mathrm{L}^{-1} \mathrm{HP}$. The HP was homogeneously introduced into the entire lake water body with a specially designed water harrow device (Matthijs et al., 2012). Within a few days, both the cyanobacterial population and the microcystin concentration collapsed for 99\%. Cyanobacterial biomass remained very low until 7 weeks after the treatment, which was much longer than initially expected (Matthijs et al., 2012).

The higher sensitivity to HP-exposure of cyanobacteria as compared to eukaryotic phytoplankton is based upon a marked difference in their coping strategy to reduce high light-stress. When higher plants and eukaryotic algae are exposed to high light, HP is produced biologically as a waste product of photosynthesis (Asada, 2000, 2006; Apel and Hirt, 2004). High light causes an excess of photosynthetic electron flow, stimulating chloroplasts of plants and eukaryotic algae, such as green algae and diatoms, to use oxygen as substitute electron acceptor resulting in the formation of superoxide (Mehler reaction, Mehler, 1951). This Reactive Oxygen Species (ROS) is subsequently enzymatically converted into HP by superoxide dismutase (Latifi et al., 2009). Thereupon, catalase transforms HP into water and oxygen or alternatively anti-ROS enzymes like ascorbate peroxidase reduce HP into water (Shigeoka et al., 2002). However, in cyanobacteria, presence of flavoproteins flv1p and flv $3 p$ excludes formation of superoxide: excess electrons are still donated to oxygen but water is produced directly without intermediary production of superoxide and HP (Helman et al., 2003, 2005; Allahverdiyeva et al., 2011, 2013). By consequence, oxidative stress levels are lower in cyanobacterial cells than in eukaryotic algae and diminish the demand for elevated presence of ROS-eliminating enzymes; especially ascorbate peroxidase is lacking in cyanobacteria (Passardi et al., 2007), rendering cyanobacteria more sensitive to HP than green algae and diatoms. This encouraged testing of HP as a selective cyanocide, and the expectations about its selective capacity to kill only cyanobacteria in the phytoplankton were proven correct (Drabkova et al., 2007b).

The published dose-response observations for HP versus cyanobacteria vary substantially and range from as much as $100 \mathrm{mg} \cdot \mathrm{L}^{-1}$ (Barrington et al., 2013) to around $60 \mathrm{mg} \cdot \mathrm{L}^{-1}$ (Gao et al., 2015) to as low as $2 \mathrm{mg} \cdot \mathrm{L}^{-1}$ and less (Barroin and Feuillade, 1986; Drabkova et al., 2007b). Although it is obvious that the higher the concentration of HP applied, the higher the efficiency of killing cyanobacteria will be, it must be argued that in a lake treatment the dose should be as low as possible to avoid killing of non-target species. The efficacy of homogeneously dosed, relatively low concentrations of HP for suppression of cyanobacteria in lake mitigation has already been demonstrated (Matthijs et al., 2012). However, next to these accomplishments, quite some other lake systems were regarded as not suitable for HP treatment by in advance testing at the moment a treatment was considered necessary by water managing authorities. In this study, we were interested in the reasons why in some cases a permissible $\mathrm{HP}$ addition of ideally less than $2.5 \mathrm{mg} \cdot \mathrm{L}^{-1}$ to maximally $5 \mathrm{mg} \cdot \mathrm{L}^{-1}$ was not sufficient for a major relapse of photosynthetic vitality. Our current working hypothesis for a successful treatment with HP is that exposure to a minimal HP concentration of $2 \mathrm{mg} \cdot \mathrm{L}^{-1}$ during 5 daylight hours is required to make a treatment effective. Hence, too rapid degradation of added HP in the lake water may bring down the HP concentration too soon after addition, which greatly reduces the effectiveness in the suppression of cyanobacteria. Depending on the initial HP dose and the initial phytoplankton density, the anti-oxidative capacity of algae (or bacteria that we did not account for in this study) in the phytoplankton causes HP to degrade partly or completely even before it can start killing cyanobacteria.

However, the obvious demand for more HP contrasts with the desired exclusion of detrimental effects on sensitive taxa like 
the zooplankter Daphnia, that preferably requires application of the lowest effective concentration of HP possible (Matthijs et al., 2012). A recent acute toxicity test in the laboratory indicates a LC50 of $5.6 \mathrm{mg} \cdot \mathrm{L}^{-1} \mathrm{HP}$ for Daphnia carinata, with the no observed effect concentration (NOAEC) estimated at $3 \mathrm{mg} \cdot \mathrm{L}^{-1}$ (Reichwaldt et al., 2012). An increased mortality for D. carinata above $3 \mathrm{mg} \cdot \mathrm{L}^{-1} \mathrm{HP}$ has been found by Barrington et al. (2013). Hence, treatments optimally require that HP degradation as catalyzed by anti-ROS enzymes should be minimal. This implies that treatments are most effective in systems with low anti-ROS capacity. To be able to predict which HP concentration would suit a treatment, in advance testing for a proper dose is essential, which includes insight into the chemical and biological rates of HP degradation.

In lakes suffering cyanobacterial nuisance, biodiversity is mostly low with only one or a few species of cyanobacteria dominating the system with major impacts on zooplankton and fish populations (Sigee, 2005; Reynolds, 2006). HP treatments in Dutch lakes have shown repeatedly that a more diverse plankton community arose after the treatment and that severe cyanobacterial blooms only reoccurred in the next growing season (Matthijs et al., 2012, and unpublished results).

In this study, we have investigated the responses of a Planktothrix-dominated natural phytoplankton community in small scale laboratory incubation experiments. We tested the effectiveness of the HP treatment in relation to phytoplankton density, recorded phytoplankton diversity changes in a 7-week succession experiment, and finally we re-inoculated HP treated water samples with fresh cyanobacteria-dominated water to assess sustainability of the HP treatment.

\section{Materials and Methods}

\section{Collection of Field Samples}

Samples were collected on September 25, 2014 from a small water body connected to a larger water system located near the laboratory of the University of Amsterdam (Science Park) at $52^{\circ} \cdot 3^{\prime} \mathrm{N} / 4^{\circ} 9^{\prime} \mathrm{E}$. The water contained a high abundance of the cyanobacterium Planktothrix agardhii. Water was sampled with an 8 L-bucket by pulling it from $1 \mathrm{~m}$ below the surface to the surface and transferred to $10 \mathrm{~L}$ plastic containers for transportation to the laboratory where the experiments took place. On the day of sampling, the ambient water temperature was $20^{\circ} \mathrm{C}$ and the day time average surface irradiation was $200 \mu \mathrm{mol}$ photons. $\mathrm{m}^{-2} \cdot \mathrm{s}^{-1}$. Samples of $200 \mathrm{~mL}$ were placed into $500 \mathrm{~mL}$-bottles and were exposed to daylight behind a SouthEast facing laboratory window at a constant temperature of $20^{\circ} \mathrm{C}$. Inside the lab a similar sun and cloud driven light prevalence was continued as outside, the light intensity was 30\% lower inside the lab. This was compensated by the thin water layer in the incubation bottles, which was substantially less deep than in the outside lake. Bottles were exposed to ambient air, and mixed daily by hand. No nutrients were added nor measured, before, during and after the experiments. We consider the ample growth of green algae and diatoms after HP treatment as clear evidence that nutrients were not limiting.

\section{Concentration and Dilution Experiment}

Three dilutions of lake samples were used: in one setting, phytoplankton was pre-concentrated; in a second, original lake water was used as collected; and in a third one the phytoplankton was diluted with lake water from which phytoplankton was removed. For the latter mild centrifugation (see below) and filtration of the supernatant through $1.2 \mu \mathrm{m}$ Whatman glass fiber filters (GF/C, CAT No. 1822-047) with vacuum aspiration were used to yield a phytoplankton-free filtrate. For concentration, aliquots of water samples were loaded in $50 \mathrm{~mL}$ Falcon tubes and centrifuged at $4000 \mathrm{rpm}$ at room temperature in a swing out rotor for 3 min effectively, without brakes applied at the end of the run. Half of the upper volume with clear supernatant was removed and the loose phytoplankton pellets from each set of two tubes were combined, to a final volume of $50 \mathrm{ml}$ again and a total of $200 \mathrm{~mL}$ was put into $500 \mathrm{~mL}$ polyethylene bottles. The resulting phytoplankton abundance in the concentrated, original lake sample, and diluted samples was estimated by PhytoPAM (Walz, Effeltrich, Germany)-assisted relative chlorophyll measurement to be 2:1:0.5. All samples of $200 \mathrm{~mL}$ were transferred to $500 \mathrm{~mL}$ plastic bottles for a time series incubation with HP at different concentrations.

\section{Hydrogen Peroxide Degradation Assay}

HP was diluted from a $3 \%$ drugstore stock solution to arrive at final concentrations of $0 ; 2.5 ; 5 ; 10 ; 20 ; 50 \mathrm{mg} \cdot \mathrm{L}^{-1}$ in the $200 \mathrm{~mL}$ described above. Just before and at 1, 2, 4, and $24 \mathrm{~h}$ after HP addition aliquots were taken from the thoroughly mixed bottles with volume sizes adjusted to attain comparable amounts of phytoplankton on the filters and compensate for concentration and dilution, and were filtrated over $1.2 \mu \mathrm{m}$ Whatman glass fiber filters (GF/C, CAT No. 1842-047) for preparation of a phytoplankton-free filtrate by vacuum aspiration using a Millipore 1225 Sampling Manifold (Cat. no xx2702550 Millipore Corp. Bedford MA USA). The filtrates were used for HP quantification, by mixing $100 \mu \mathrm{L}$ with $100 \mu \mathrm{L}$ of $p$ nitrophenyl boronic acid reagent (Sigma) in a 96-well microtiter plate according to Lu et al. (2011). HP dependent formation of di-nitrophenol (DNP) from the reagent at room temperature was complete in $30 \mathrm{~min}$ and the color remained stable for several hours. DNP was measured at $405 \mathrm{~nm}$ using a plate reader (Molecular Devices Versamax microplate reader). Alternatively, samples of $2 \mathrm{~mL}$ were spun down in a microfuge at 10,000 rpm, and $100 \mu \mathrm{L}$ of the supernatant was used for the HP assay.

\section{Photosynthetic Vitality Assay by Mini-PAM}

The phytoplankton retained on the filters was used for a photosynthetic vitality assay. Photosynthetic yield was estimated with a Mini-PAM instrument according to the online user manual provided by the manufacturer (Walz, Effeltrich, Germany). The instrument was equipped with a wide bore $(0.8 \mathrm{~cm})$ light fiber guide, which was mounted in a stopper of the Millipore filtration apparatus. Samples on filters were left on the Millipore manifold support and rubber stoppers served to establish dark-adaption for $10 \mathrm{~min}$. For a measurement the rubber stopper was rapidly exchanged by the stopper in which the miniPAM probe was mounted. Photosynthetic 
yield estimation followed the standard pre-set instrument protocol. While collecting phytoplankton on filters, any impact of differences in sample density were corrected by using $4 \mathrm{~mL}$ of the concentrated sample, $8 \mathrm{~mL}$ of the original lake sample and $16 \mathrm{~mL}$ of the diluted sample. All samples were that way measured at the same amplification setting, which permitted use of the $0 \mathrm{mg} \cdot \mathrm{L}^{-1}$ untreated control to set the corresponding photosynthetic yield as the $100 \%$ photosynthetic vitality value. Though, the Mini-PAM assay for photosynthetic vitality does not permit to discriminate between different phytoplankton species, the fluorescence emission signal of the phytoplankton on filters proved very stable and similarly the determined effective quantum yield of PSII photochemistry, which followed from F0, Fm, and Fm' after a saturating pulse, using the preset software of the instrument, as based on Schreiber (2004).

\section{Relative Phytoplankton Species Prevalence by Phyto-PAM}

To determine the change in the phytoplankton community composition, the relative fluorescence was measured with a Phyto-PAM Phytoplankton Analyser. Samples of the various incubations were directly introduced into polystyrene $3 \mathrm{~mL}$ four sides clear fluorescence cuvettes. The Phyto-PAM instrument measures reaction center fluorescence emission after subsequent excitation with four wavelengths of $665,645,520$, and $470 \mathrm{~nm}$ and transforms the emitted fluorescence signals into the approximate presence of three differently pigmented algal groups: cyanobacteria, green algae, and diatoms/dinoflagellates based on preloaded excitation/emission files of representative species of each algal group. In this study we recorded and preloaded files for laboratory cultures of the cyanobacterium Microcystis aeruginosa (strain PCC 7806), the green alga Chlorella pyrenoidosa, and the diatom Phaeodactylum tricornutum as internal instrument references (see Supplementary Figures 1 and 2). In the PhytoPAM assay, the relative differences in biomass prevalence are reported as differences in fluorescence intensity $\mathrm{F}_{0}$, as described in the user manual provided by the manufacturer (c.f. Schreiber, 2004). The Phyto-PAM assay was used just before and 4 days after HP addition to estimate changes in the relative presence of the three main phytoplankton groups.

\section{Succession Experiment}

Lake water samples (cf. Figure 1) were treated with HP to arrive at final HP concentrations of 0 (control); $2.5 ; 5 ; 10 ; 20$; $50 \mathrm{mg} \cdot \mathrm{L}^{-1}$, and were put at a South West facing window site in the laboratory. To determine succession in the phytoplankton community in time, the relative fluorescence was measured with a Phyto-PAM (pulse amplitude modulation) fluorometer at the time points: 0 (at start); $4 ; 7 ; 11 ; 15 ; 25 ; 32$; and 49 days after HP addition. Since Phyto-PAM fluorescence provides no absolute numbers for phytoplankton abundance, microscopical analysis was used to confirm the established taxa discrimination and to determine actual cell numbers and biovolume. Cell counts are reported for a time point at 25 days after $\mathrm{HP}$ addition for $0,2.5,5$, and $10 \mathrm{mg} \cdot \mathrm{L}^{-1}$ (for microscopy technical description, see below).

\section{Re-inoculation Experiment}

Fresh water samples were taken on October 62014 to reinoculate the samples that were treated with HP 7 days earlier (see "Succession experiment" above). The fresh water was mixed with HP treated samples at a ratio of 1:2 (fresh:treated). Prior to mixing, estimation of $\mathrm{HP}$ concentrations verified that $\mathrm{HP}$ was no longer detectable even in the samples with the highest added concentrations. As a measure for the relative abundance of different taxa, the relative fluorescence emission was obtained with the Phyto-PAM instrument (Walz, Effeltrich, Germany) just

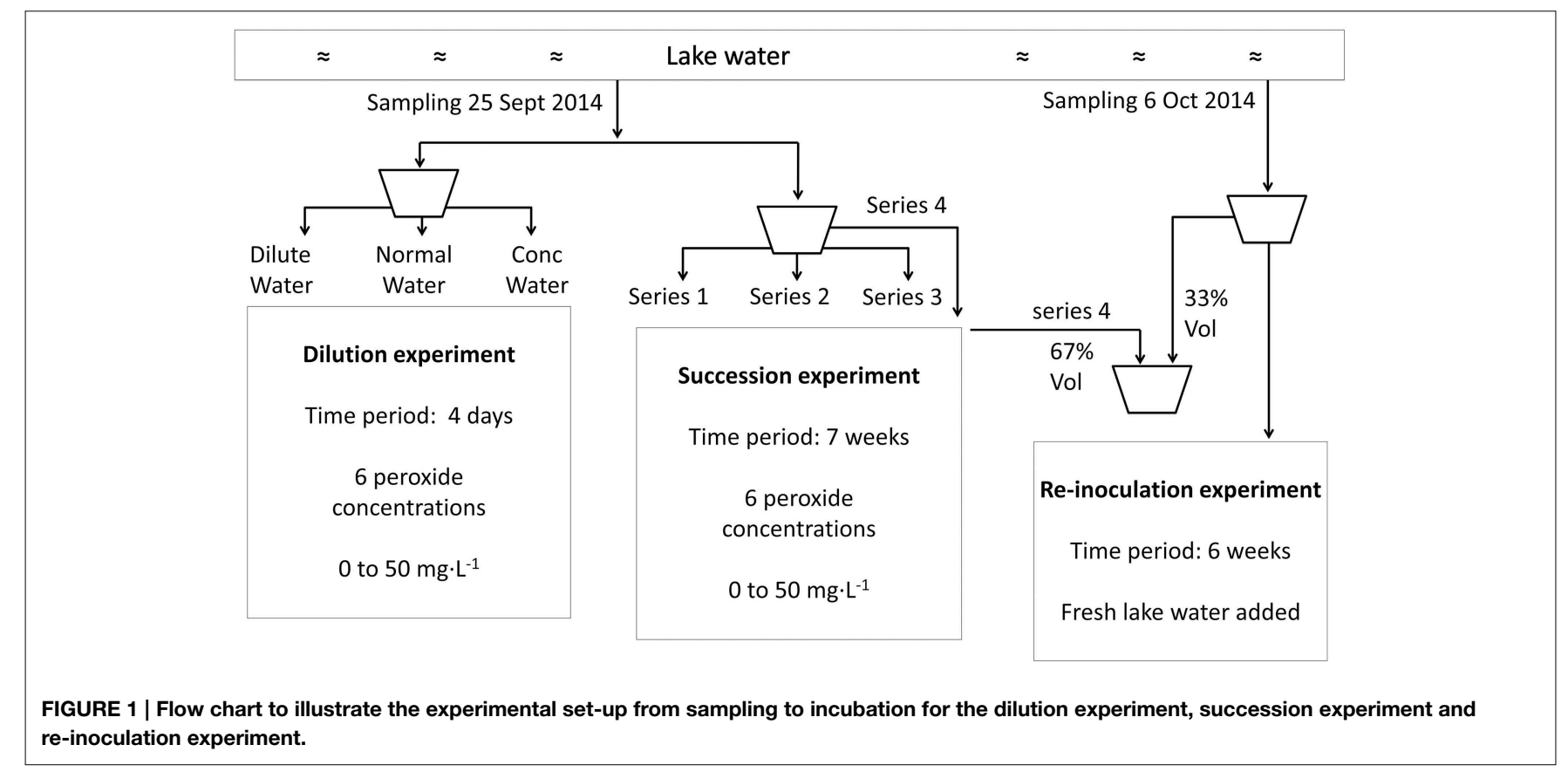


before the start at day 0 and at $4,8,18,25$, and 42 days after mixing.

Succession of the mixture was compared with the continued succession of the original treated series (to which no fresh water was added) and with succession of the untreated fresh water. Furthermore, at each measuring moment the expected fluorescence in imaginary instantly assembled mixtures was calculated to determine the expected community composition in case no biological community effects would have played a role.

\section{Microscopy}

The phytoplankton samples were fixed with Lugol's Iodine. The phytoplankton was identified to genus level, and if possible to the species level, and counted using an inverted microscope using the Utermöhl-method (Utermöhl, 1958) adjusted to a European standard protocol (NEN-EN 15204, 2006). Biovolume was estimated by multiplying cell number and a standard volume for a single cell of that taxon. This volume is derived from the volume of a standard mathematical body which resembles the shape of the cell best (e.g., sphere, cylinder, spindle) using average cell dimensions based on commonly used books for determination (Komárek and Fott, 1983; Krammer and LangeBertalot, 1986-1991; Komárek and Anagnostidis, 2005; Coesel and Meesters, 2007).

\section{Data Analysis}

One-Way ANOVA analysis (test statistic F) followed by Tukey's pairwise comparison (test statistic Q) was conducted when four means were compared. A two-sample $t$-test was used for comparing two means. The Simpson-Dominance index (Krebs, 1989; Hillebrand and Sommer, 2000) was used to compare the dominance of a single species under different environmental conditions or similar habitats and ranges from 0 , where all taxa are equally present to 1 , where one taxon dominates the community completely:

$$
D=\sum\left(\left(\frac{n i}{N}\right)^{2}\right)
$$

Where $D=$ Simpson - Dominance index (hereafter called the Dominance index), $n_{i}=$ number of cells of each taxon (the ith taxon), and $N=$ total number of cells from the sample.

The Shannon-Wiener diversity index (Shannon and Weaver, 1949), which is a function of taxa richness and evenness, was used to measure phytoplankton diversity. The index is maximal when all taxa are equally abundant in a community:

$$
H^{\prime}=-\sum\left[\left(\frac{n i}{N}\right) \times \ln \left(\frac{n i}{N}\right)\right]
$$

Where: $H^{\prime}=$ Shannon diversity index, $n_{i}=$ number of cells of each taxon (the ith taxon), and $N=$ total number of cells from the sample.

Statistical analysis and calculating indices have been performed by PAST (Jin and Copper, 2008).

\section{Results}

\section{Relation of Phytoplankton Abundance, HP Degradation and Photosynthetic Vitality}

Using three phytoplankton densities (2:1:0.5 ratio), the rate of degradation of added HP is shown in Figure 2. The disappearance of HP was appreciably faster in the concentrated sample (Figure 2A) than in the original lake sample (Figure 2B) and in the diluted sample (Figure $2 \mathrm{C}$ ). As a result, no HP could be detected in samples treated with a dose of 2.5 and $5 \mathrm{mg} \cdot \mathrm{L}^{-1}$ for concentrated water $4 \mathrm{~h}$ after addition, but in the diluted sample 0.4 and $4.2 \mathrm{mg} \cdot \mathrm{L}^{-1} \mathrm{HP}$ of the 2.5 and $5 \mathrm{mg} \cdot \mathrm{L}^{-1}$ additions respectively were still retrieved. After $24 \mathrm{~h}$, all $\mathrm{HP}$ was degraded in the concentrated water sample, except for the highest dose of $50 \mathrm{mg} \cdot \mathrm{L}^{-1}$, which was still present at $6.3 \mathrm{mg} \cdot \mathrm{L}^{-1} \mathrm{HP}$ and of the similar start concentration the diluted water sample still contained $24.9 \mathrm{mg} \cdot \mathrm{L}^{-1} \mathrm{HP}$ after $24 \mathrm{~h}$. The original lake sample showed no more traces of added HP below $5 \mathrm{mg} \cdot \mathrm{L}^{-1}$ after $24 \mathrm{~h}$; but of the dose of $10 \mathrm{mg} \cdot \mathrm{L}^{-1} 1.8 \mathrm{mg} \cdot \mathrm{L}^{-1} \mathrm{HP}$ was still present (Figure 2B).

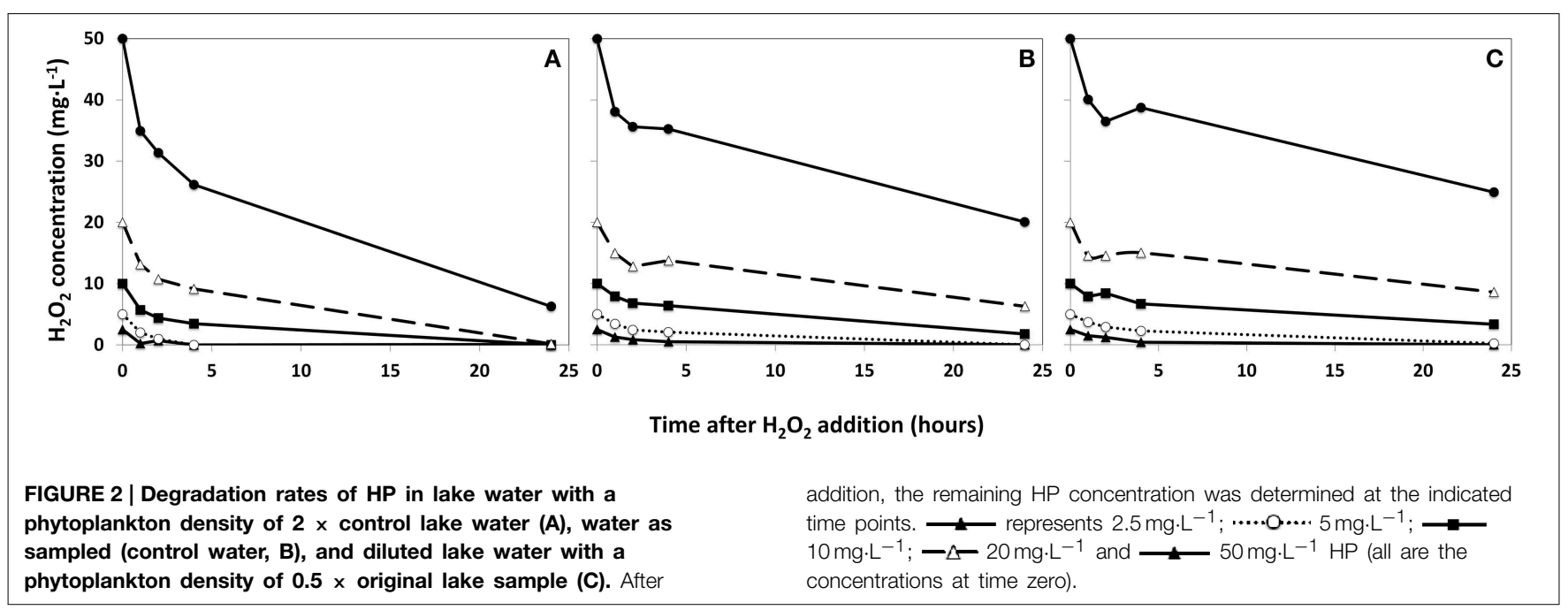


The decline of the photosynthetic vitality in the phytoplankton exposed to HP was studied at $4,24 \mathrm{~h}$, and 4 days after HP addition in samples concentrated on membrane filters using the Mini-PAM instrument. Note that the decline for the concentrated sample displayed in Figure 3A is appreciably less than in the original lake sample (Figure 3B) and in the diluted sample (Figure 3C). Moreover, in the concentrated sample at all HP concentrations added, the fluorescence signal increases again after 4 days. However, for the original lake samples and diluted samples, only the lowest concentration of $2.5 \mathrm{mg} \cdot \mathrm{L}^{-1}$ showed renewed vitality after $24 \mathrm{~h}$ (Figures 3B,C) and all of the higher concentrations of added HP demonstrated a further decline until below the detection limit after 4 days.

The water samples that were not treated with HP $\left(0 \mathrm{mg} \cdot \mathrm{L}^{-1}\right)$ demonstrated growth of cyanobacteria after 4 days as determined by the Phyto-PAM (Figure 4). The concentrated sample showed fluorescence emission of cyanobacteria for all HP additions, including the highest $50 \mathrm{mg} \cdot \mathrm{L}^{-1}$ dose. For the original lake sample HP supplied at a dose of $5 \mathrm{mg} \cdot \mathrm{L}^{-1}$ and higher, fluorescence signals became prominent for green algae and diatoms, and relapsed for cyanobacteria although a small signal $(<15 \%)$ of cyanobacteria was detected for the $20 \mathrm{mg} \cdot \mathrm{L}^{-1}$ test in the original lake sample water (Figure 4B). In the diluted sample, no signal from cyanobacteria was detected at any of the applied HP concentrations including the $2.5 \mathrm{mg} \cdot \mathrm{L}^{-1}$ one. In these samples only signals from green algae and diatoms were retained. Note that the samples are studied as the original liquid suspension and the absolute height of the fluorescence is decreasing from concentrated water via original lake sample to diluted water, which is the direct consequence of the $2,1,0.5$ phytoplankton concentration ratio's in the water sample and is not related to $\mathrm{HP}$ dosing.

\section{Species Succession Observed by Phyto-PAM}

Changes in the composition of the phytoplankton community as a function of HP addition at time zero have been followed during 49 days (Figure 5). In the samples without added HP, fluorescence signals indicate a gradual decrease in cyanobacteria abundance after 4-7 days and a substantial increase in green algae and diatoms after 15-25 days and onwards in the untreated samples, a similar change was seen in the outside lake water (data not shown) (Figure 5A). However, in the presence of HP the succession of the dominant Planktothrix in the original sample to green algae and diatoms not only started earlier (already after 2-4 days at a HP dose of $2.5 \mathrm{mg} \cdot \mathrm{L}^{-1}$ ), but also became more prominent (Figure 5B). The actual apparent population
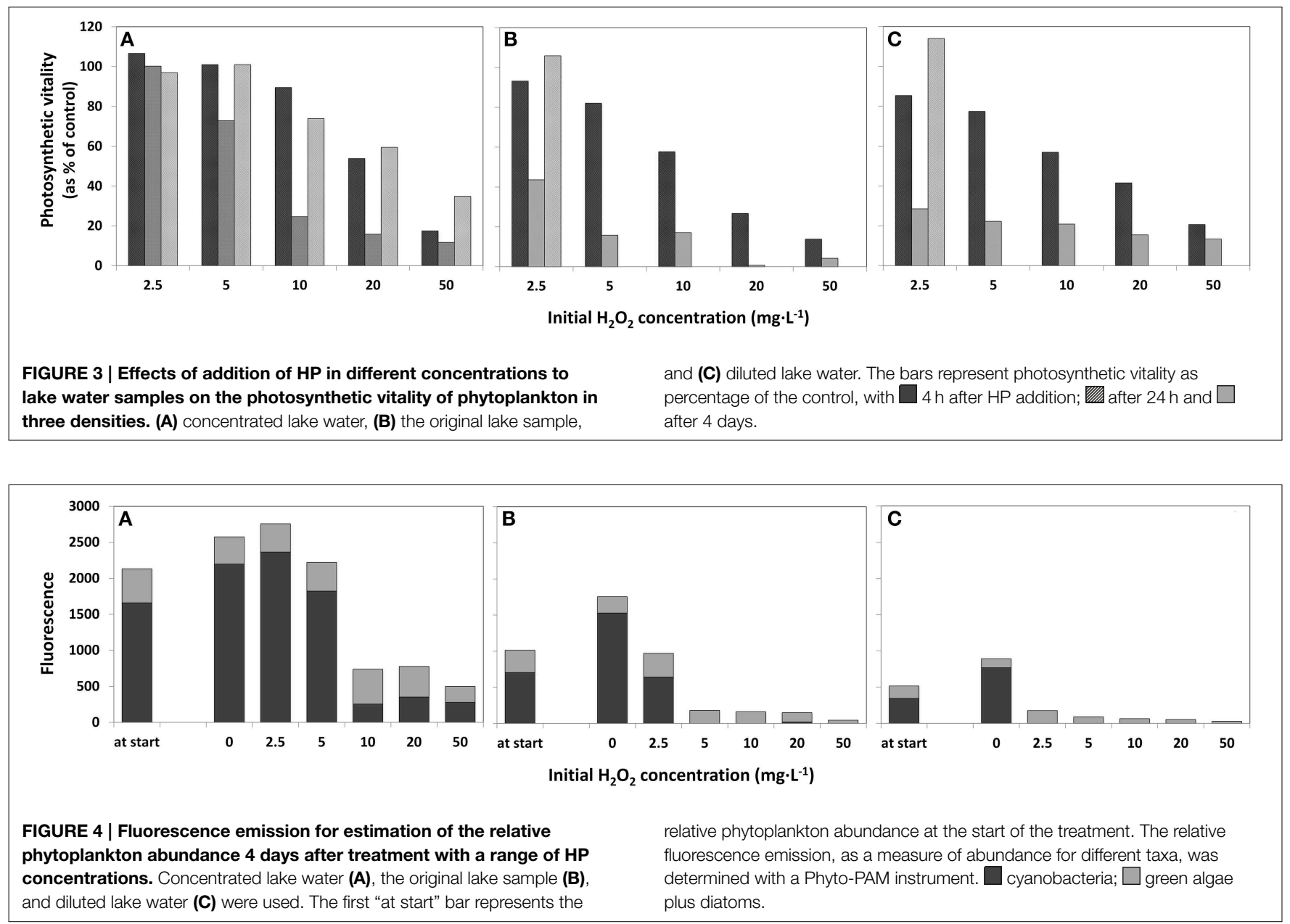


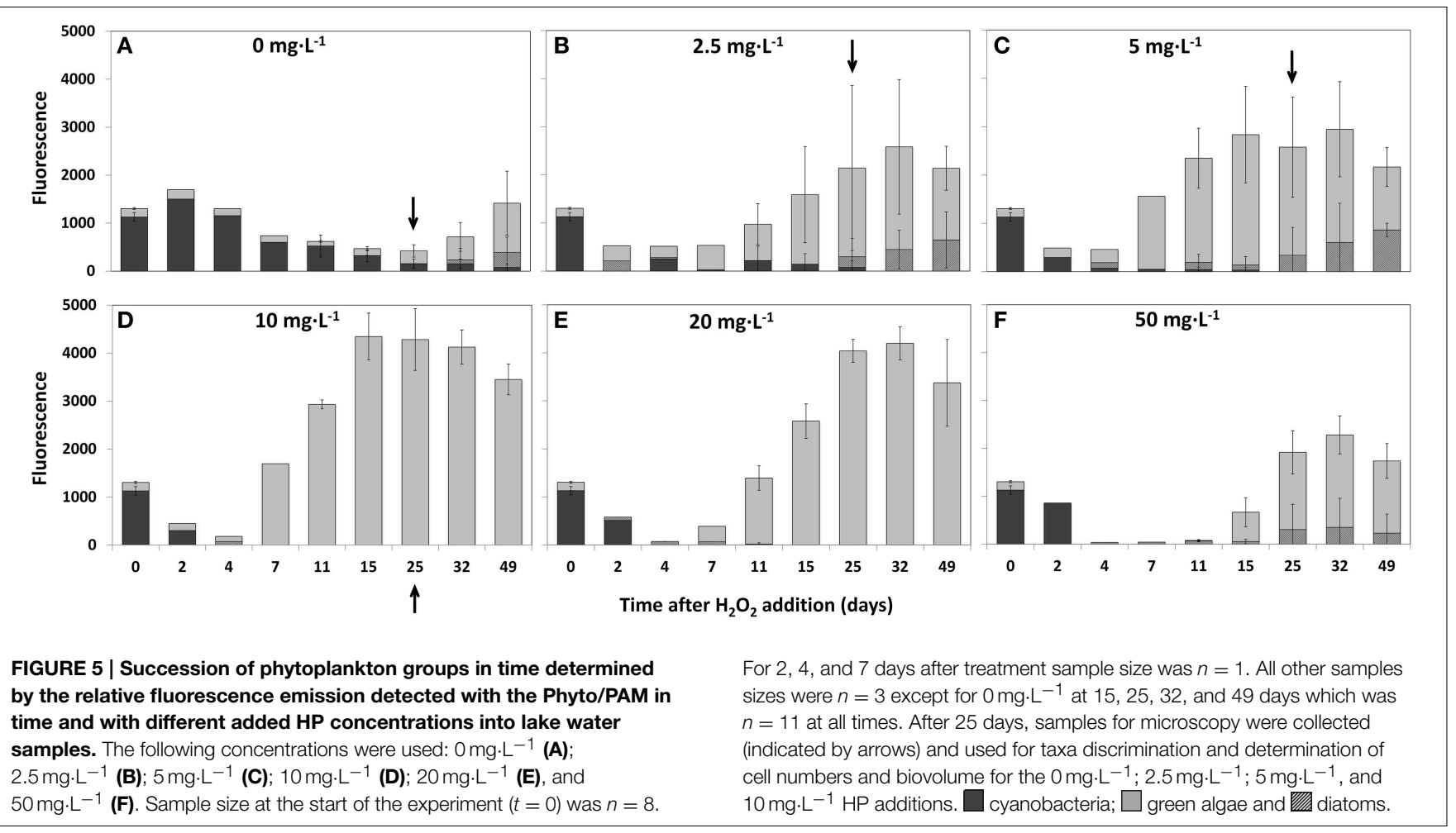

density as estimated by the total fluorescence signal exceeds the control after 11 days. This trend developed even more when applied HP doses increased (Figures 5C,D). Further increase of the doses to 20 and especially $50 \mathrm{mg} \cdot \mathrm{L}^{-1}$ impeded these trends (Figures 5E,F). Diatoms became more abundant after 25 days in the 2.5 and $5 \mathrm{mg} \cdot \mathrm{L}^{-1}$ treatments (Figures $\mathbf{5 B}, \mathbf{C}$ ), but were no longer found in the $10 \mathrm{mg} \cdot \mathrm{L}^{-1}$ treatment while the signal of the green algae is still increasing (Figure 5D). At $50 \mathrm{mg} \cdot \mathrm{L}^{-1}$, where the green algae abundance decreased, diatoms (possibly of a different peroxide resistant kind) were apparent again (Figure 5F).

The increase in fluorescence cyanobacteria signal 2 days after treatment for the different samples is remarkable. Measurements indicate no presence of cyanobacteria for the lowest dose of $2.5 \mathrm{mg} \cdot \mathrm{L}^{-1} \mathrm{HP}$ but the signal arose at $5 \mathrm{mg} \cdot \mathrm{L}^{-1}$ and increased when doses increased. This aberrant increase was strongly temporal, and is possibly related to fluorescence from detached phycobilin pigments that are specifically excited in the PhytoPAM assay and started to dissappear after 4 days.

\section{Changes in Phytoplankton Composition Counted by Microscopy}

After 25 days, microscopy was used for comparison to the PhytoPAM data and in particular for taxa discrimination in the control $\left(0 \mathrm{mg} \cdot \mathrm{L}^{-1}\right)$ and HP-treated water samples. Table 1 displays the results for the control and $2.5 \mathrm{mg} \cdot \mathrm{L}^{-1}$ (the remaining full data including 5 and $10 \mathrm{mg} \cdot \mathrm{L}^{-1}$ are presented in Supplementary Tables 1 and 2). All of the four HP concentrations showed considerable differences in cell densities of the main phytoplankton groups, among each other and within replicates
(Figure 6A). The three control samples were nearly completely dominated by Planktothrix, with cell numbers ranging between $1.78 \cdot 10^{6}$ and $5.62 \cdot 10^{6}$ cells $\cdot \mathrm{mL}^{-1}$. Two replicates of the lowest $2.5 \mathrm{mg} \cdot \mathrm{L}^{-1}$ dose were free from cyanobacteria; however, the third replicate was still quite strongly dominated by Planktothrix: $1.29 \cdot 10^{6}$ cells $\cdot \mathrm{mL}^{-1}$. One replicate of the $5 \mathrm{mg} \cdot \mathrm{L}^{-1}$ dose was free from cyanobacteria, and the other two replicates contained Planktothrix ranging between $0.94 \cdot 10^{6}$ and $1.38 \cdot 10^{6}$ cells $\cdot \mathrm{mL}^{-1}$. The $10 \mathrm{mg} \cdot \mathrm{L}^{-1}$ dose still had cyanobacteria present in two replicates, although in small numbers ranging between $0.08 \cdot 10^{6}$ and $0.51 \cdot 10^{6}$ cells $\cdot \mathrm{mL}^{-1}$. The contribution of green algal cells in the control community was very small and ranged between $0.03 \cdot 10^{6}$ and $0.12 \cdot 10^{6}$ cells $\mathrm{mL}^{-1}$. The two replicates of the lowest $2.5 \mathrm{mg} \cdot \mathrm{L}^{-1}$ dose without cyanobacteria, were dominated by green algae and cell numbers range between $0.89 \cdot 10^{6}$ and $2.00 \cdot 10^{6}$ cells $\cdot \mathrm{mL}^{-1}$, where the third replicate (that still contained cyanobacteria) only showed $0.09 \cdot 10^{6}$ cells $\cdot \mathrm{mL}^{-1}$. Green algal cells in samples treated with $5 \mathrm{mg} \cdot \mathrm{L}^{-1} \mathrm{HP}$ were considerably more abundant and range between $0.78 \cdot 10^{6}$ and $3.26 \cdot 10^{6}$ cells $\cdot \mathrm{mL}^{-1}$ and in samples with the $10 \mathrm{mg} \cdot \mathrm{L}^{-1}$ dose demonstrated the highest abundances ranging between $2.50 \cdot 10^{6}$ and $3.52 \cdot 10^{6}$ cells $\cdot \mathrm{mL}^{-1}$. Diatoms never reached high abundances but showed a slight increase in the treated samples: maximally $0.13 \cdot 10^{6}$ cells $\cdot \mathrm{mL}^{-1}$ were counted, compared to the control samples, which displayed maximally $0.04 \cdot 10^{6}$ cells $\cdot \mathrm{mL}^{-1}$.

\section{Average Cell Density and Biovolume by Microscopical Analysis}

On average, total cell densities determined 25 days after treatment, were not significantly different between different 
TABLE 1 | Numbers of cells (cells $\cdot \mathrm{mL}^{-1}$ ) of different taxa as observed by bright field microscopy.

\begin{tabular}{|c|c|c|c|c|c|c|}
\hline TAXA & \multicolumn{3}{|c|}{ Control (0 mg. $\left.\mathrm{L}^{-1} \mathrm{HP}\right)$} & \multicolumn{3}{|c|}{ Treated $\left(2.5 \mathrm{mg} \cdot \mathrm{L}^{-1} \mathrm{HP}\right)$} \\
\hline CYANOBACTERIA-TOTAL & $1,821,818$ & $5,620,364$ & $1,774,545$ & & & $1,287,273$ \\
\hline Chlorophyta & 15,789 & 8525 & 26,885 & 407,139 & 291,228 & 24,918 \\
\hline Crucigeniella & & & 2623 & 28,070 & & \\
\hline Desmodesmus & 42,105 & 20,984 & 60,328 & $1,471,429$ & 365,517 & 43,934 \\
\hline Dictyosphaerium & & & & & 203,509 & \\
\hline Monoraphidium & 9211 & 2000 & 20,364 & 3509 & & 3279 \\
\hline \multicolumn{7}{|l|}{ Tetrastrum } \\
\hline GREEN ALGAE-TOTAL & 125,000 & 61,016 & 212,054 & $3,885,833$ & $1,557,561$ & 174,450 \\
\hline Achnanthidium & 439 & 4590 & 10,492 & 17,544 & 3509 & 656 \\
\hline Aulacoseira & & & & 91 & & \\
\hline Cymbella & & & & 182 & & \\
\hline Fragilaria & & & 1455 & 818 & 2545 & \\
\hline Navicula & & & & 91 & 364 & \\
\hline Nitzschia & 1754 & 10,182 & 22,545 & 4000 & 38,545 & 17,455 \\
\hline Ulnaria & & 182 & 2545 & 4182 & 1091 & 2182 \\
\hline
\end{tabular}

Samples from technical replicates $(n=3)$ of control water $\left(0 \mathrm{mg} \cdot \mathrm{L}^{-1} \mathrm{HP}\right)$ and treated water $\left(2.5 \mathrm{mg} \cdot \mathrm{L}^{-1} \mathrm{HP}\right)$ were collected 25 days after HP addition.

treatments [Figure 6A; One-Way ANOVA, $d f=2, F=1.062$, $p=0.418$ ]. A clear succession was visible with increasing HP concentrations, from a Planktothrix-domination in control samples to a domination of green algae, even with the lowest HP concentration of $2.5 \mathrm{mg} \cdot \mathrm{L}^{-1}$. A similar trend was observed in the biovolume shares of the main phytoplankton groups, but the total biovolume did not differ significantly between the different treatments (Figure 6B; One-Way ANOVA, $d f=2$, $F=3.142, p=0.087)$. Due to different cell volumes per taxa, differences between main groups became, on average, more apparent. Diatoms contributed considerably to the community biovolume but never became dominant. The $2.5 \mathrm{mg} \cdot \mathrm{L}^{-1} \mathrm{HP}-$ treated samples showed on average a small decrease in total biovolume, compared to the control samples. When the doses increased, total biovolumes also tended to increase to values considerably larger than the average control samples, which is largely caused by green algal growth.

Compared to the control samples, cyanobacterial biovolumes as percentage of total biovolume, significantly decreased in the $2.5 \mathrm{mg} \cdot \mathrm{L}^{-1} \mathrm{HP}$ dose $\left[d f=2, Q_{(0,2.5)}=5.61, p=0.018\right]$; in the $5 \mathrm{mg} \cdot \mathrm{L}^{-1}$ dose $\left[d f=2, Q_{(0,5)}=5.99, p=0.012\right]$ and in the $10 \mathrm{mg} \cdot \mathrm{L}^{-1}$ dose $\left[d f=2, Q_{(0,10)}=7.04, p=0.005\right]$ (Figure 7A). Biovolumes of green algae increased significantly in the $10 \mathrm{mg} \cdot \mathrm{L}^{-1} \mathrm{HP}$ dose compared to the control [Figure $7 \mathbf{B}$; $\left.d f=2, Q_{(0,10)}=6.81, p=0.006\right]$, where the $2.5 \mathrm{mg} \cdot \mathrm{L}^{-1}$ dose and the $5 \mathrm{mg} \cdot \mathrm{L}^{-1}$ dose already showed substantial and nearly significant increased compared to the control biovolume $[d f=2$, $\left.Q_{(0,2.5)}=4.24, p=0.067\right]$ and $\left[d f=2, Q_{(0,5)}=4.38, p=\right.$ $0.058]$, respectively. Diatoms as percentage of total biovolume did not change between treatments (Figure 7C; $d f=2, F=1.574$, $p=0.418)$.

\section{Biodiversity in HP Treated Samples}

Taxa richness in the different samples was the same in control and all treatments (Figure 8A; $d f=2, F=0.32, p=0.814$ ). However, compared to the control samples, the Dominance index significantly decreased for the $5 \mathrm{mg} \cdot \mathrm{L}^{-1} \mathrm{HP}$ dose [Figure 8B; $\left.d f=2, Q_{(0,5)}=6.64, p=0.007\right]$ and for the $10 \mathrm{mg} \cdot \mathrm{L}^{-1}$ dose $\left[d f=2, Q_{(0,10)}=6.17, p=0.010\right]$. The $2.5 \mathrm{mg} \cdot \mathrm{L}^{-1} \mathrm{HP}$ dose did not change significantly in Dominance index although a decreasing trend could be observed [Figure $8 \mathbf{B} ; d f=2, Q_{(0,2.5)}=$ $3.88, p=0.095$ ]. Shannon diversity index significantly increased 

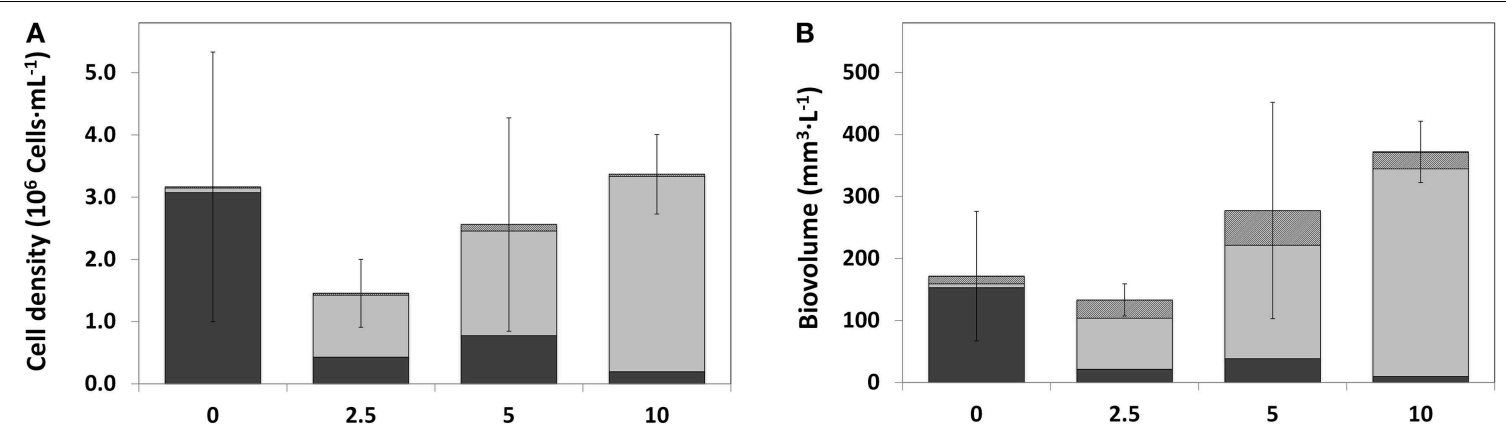

Initial $\mathrm{H}_{2} \mathrm{O}_{2}$ concentration (mg. $\mathrm{L}^{-1}$ )

FIGURE 6|Cell densities of the main phytoplankton groups as observed by bright field microscopy, for control water $\left(0 \mathrm{mg} \cdot \mathrm{L}^{-1}\right) \mathrm{HP}$ and treated water $\left(2.5 ; 5 ; 10 \mathrm{mg} \cdot \mathrm{L}^{-1}\right), 25$ days after HP addition. (A) Average cell density per HP dose $(n=3)$;
(B) Average biovolume per HP dose $(n=3)$. Error bars represent standard deviations of total cell density (A) and total biovolume (B). $\square$ cyanobacteria; $\square$ green algae; $\mathbb{R}$ diatoms and $\square$ other taxa.
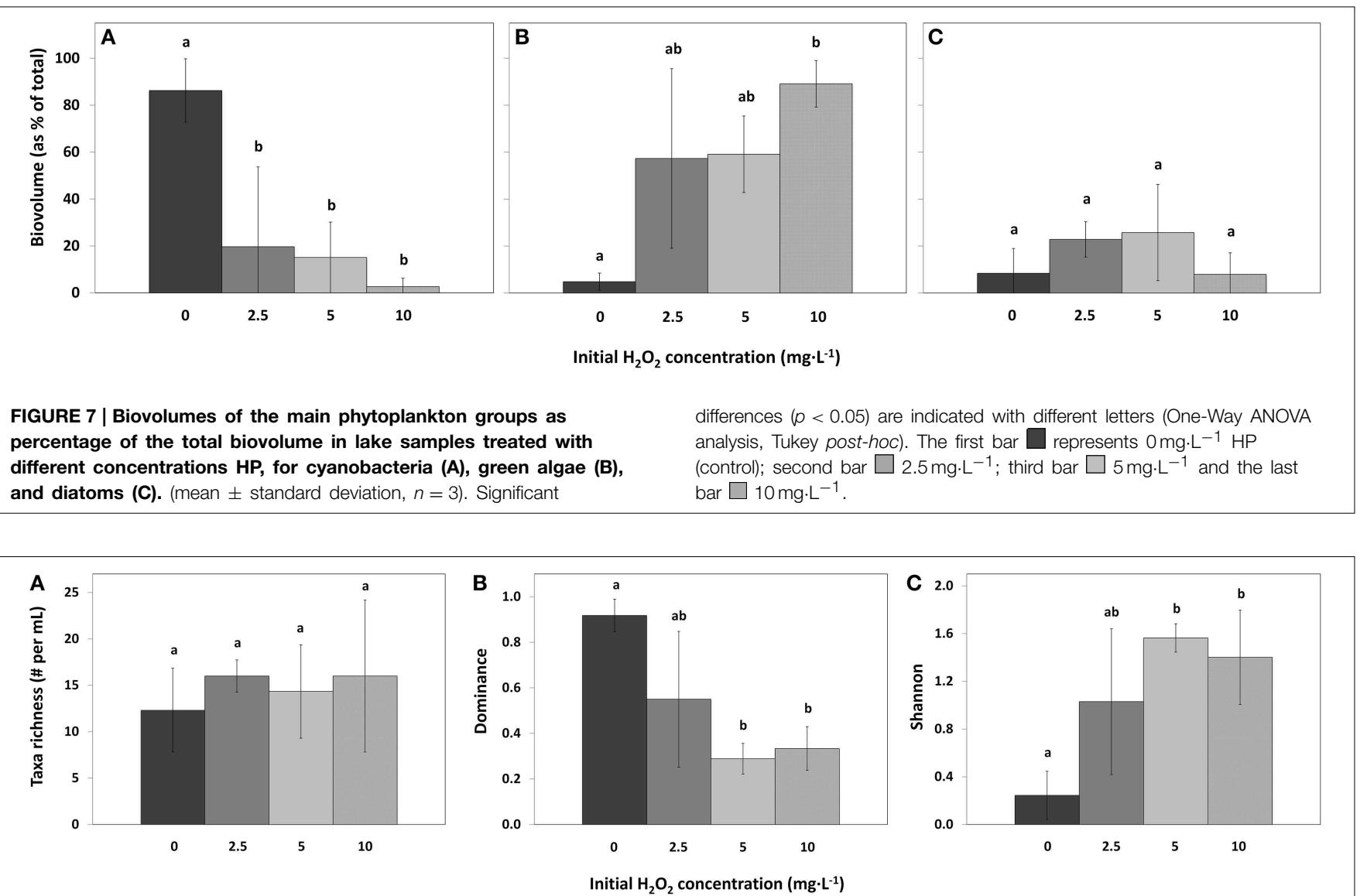

FIGURE 8 | Taxa richness (A), Simpson-Dominance index (B), and Shannon diversity index (C) of the phytoplankton in lake samples treated with different concentrations of HP (mean \pm standard deviation, $\boldsymbol{n}=3$ ). Significant differences $(p<0.05)$ are indicated with

different letters (One-Way ANOVA analysis, Tukey post-hoc). Taxa found in the samples but not counted in large numbers were not used for the analysis. The first bar $\square$ represents $0 \mathrm{mg} \cdot \mathrm{L}^{-1} \mathrm{HP}$ (control); second bar $\square$ $2.5 \mathrm{mg} \cdot \mathrm{L}^{-1}$; third bar $\square 5 \mathrm{mg} \cdot \mathrm{L}^{-1}$ and the last bar $\square 10 \mathrm{mg} \cdot \mathrm{L}^{-1}$.

for the $5 \mathrm{mg} \cdot \mathrm{L}^{-1}$ dose [Figure 8C; $d f=2, Q_{(0,5)}=5.97$, $p=0.013]$ and for the $10 \mathrm{mg} \cdot \mathrm{L}^{-1}$ dose $\left[d f=2, Q_{(0,10)}=\right.$ 5.24, $p=0.025]$, compared to the control samples. The
$2.5 \mathrm{mg} \cdot \mathrm{L}^{-1}$ dose did not change significantly, but an increasing trend could be observed [Figure $8 C$; $d f=2, Q_{(0,2.5)}=3.56$, $p=0.132]$. 


\section{Re-inoculation of HP Treated Samples with Planktothrix-Rich Fresh Lake Water}

Lake water samples treated with $2.5 ; 5 ; 10$; and $20 \mathrm{mg} \cdot \mathrm{L}^{-1}$ HP were mixed with fresh lake water after 7 days, and the development of the composition of the phytoplankton community was followed for 42 days by Phyto-PAM (Figure 9). After an initial increase of fluorescence emission from the newly added cyanobacteria, cyanobacterial fluorescence disappeared in all treated mixtures 8 days after mixing with fresh lake water. In contrast, the cyanobacteria flourished in the inlet water. The appreciably lower prevalence of fluoresence from cyanobacteria in the third set (actually measured) relative to the fourth set (calculated result if fresh water and treated water would have been mixed at that point in time) represents prolonged cyanocidal effects in the treated samples until long after all HP had disappeared. The sustained cyanocidal effect is accompanied by an increased presence of green algae for all of the four HP concentrations tested.

\section{Discussion}

HP changes the composition of a phytoplankton community by killing cyanobacteria in lake samples and subsequently facilitating growth of eukaryotic phytoplankton. The effectiveness depends on the biomass concentration of the phytoplankton in the original sample. HP treatment not only successfully combats the "bad" cyanobacteria in a phytoplankton population; additionally, by doing so, it greatly supports takeover by the "good" eukaryotic phytoplankton, which significantly increases biodiversity and may support efforts for ecosystem health recovery.

\section{How Much HP has to be Added for Selective Suppression of Cyanobacteria and at which Density of the Phytoplankton?}

In this study, we show that HP degradation is determined by the biomass density. Though use of more HP would seem an obvious solution, we advocate against such a conclusion: it is our conviction that when too much HP would be required to counteract its decrease, a treatment should not be considered. At present we recommend to use minimally $2.3 \mathrm{mg} \cdot \mathrm{L}^{-1}$ for a treatment; this is sufficent to counteract a slight loss of HP from reductive power rendered by solutes in the water and biodegradation by the assembly of living matter (microbes, phytoplankton, zooplankton, macrophytes) in the waterbody, that is including prokaryotes other than cyanobacteria that may thrive anti-ROS capacity. The recommended HP addition value may be raised in case the reductive power of the water
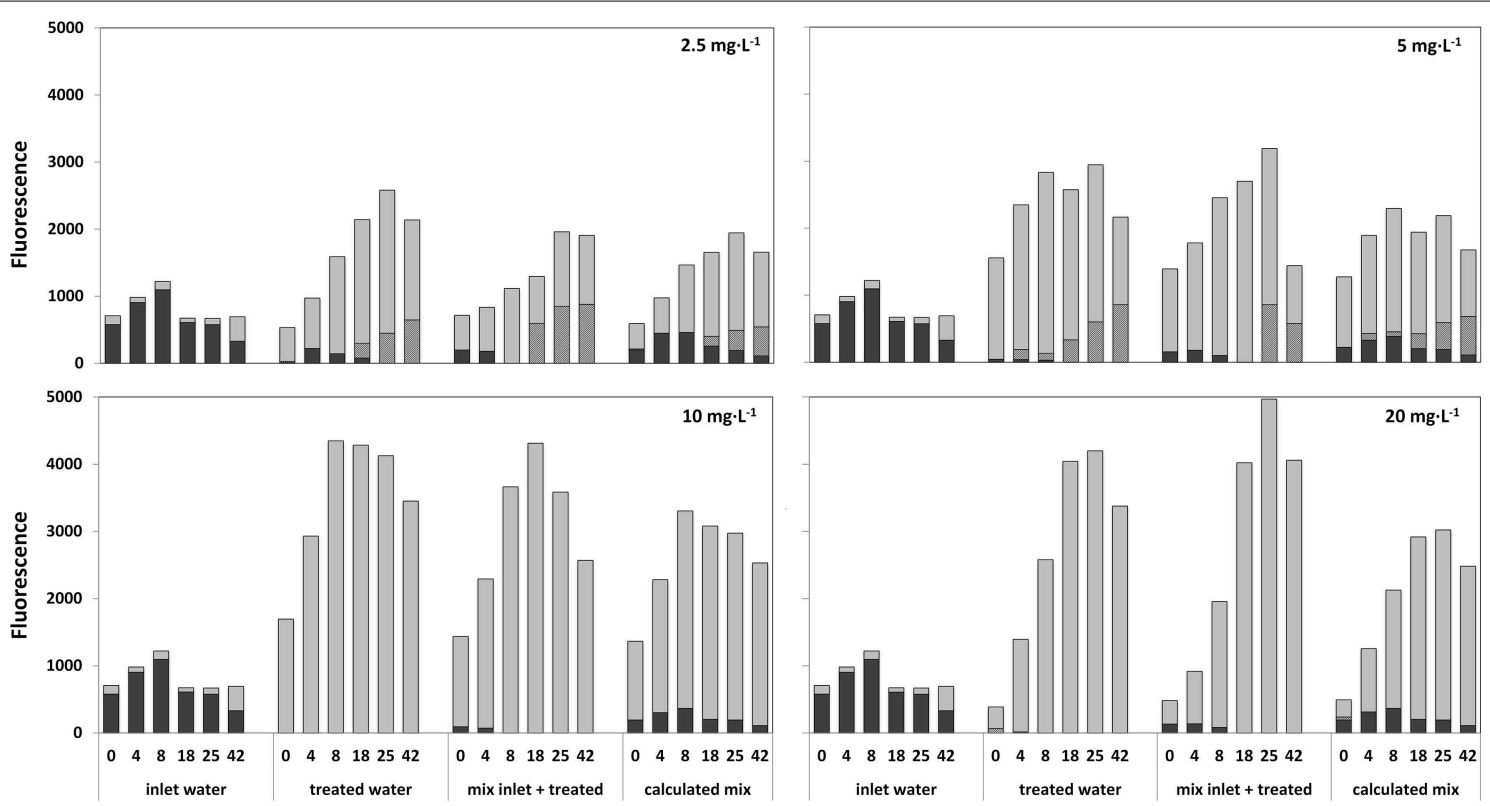

Time (days)

FIGURE 9 | Relative fluorescence emissions, as a measure of abundance for different taxa (determined with the Phyto-PAM) in time after mixing of fresh untreated lake water with water 7 days after treatment at a ratio of 1:2 (inlet:treated). Used HP concentrations of treated water were: $2.5 ; 5 ; 10$; and $20 \mathrm{mg} \cdot \mathrm{L}^{-1}$. Each figure consists of four segments with reported time series starting at day 0 (start mixing) and 4; 8; 18; 25; and 42 days after mixing. Immediately after mixing, fluorescence of the inlet water (first set of bars), the HP treated water (2nd set of bars) and the mixture (3rd set) were measured. Additionally, the calculated mean of the mixture was determined, by numerically adding the values at the time points indicated of inlet and treated water (4th set of bars). After 4 to 42 days, succession in the three samples is followed by Phyto-PAM assisted measuring of taxa-specific fluorescence for bar sets 1 and 2 and by calculating the theoretical fluorescence resulting from addition of one part fresh and two parts of treated water for each of the time points shown. Comparison of the third bar sets "mix inlet + treated" and the 4th bar sets that shows calculated outcomes if no delayed HP effects would have happened, displays how the mixture actually develops at the different HP values for treated cells. $\square$ cyanobacteria; $\square$ green algae and $\mathbb{Z}$ diatoms. 
chemistry neutralizes a partition of typically $0.1 \mathrm{up}$ to $1.2 \mathrm{mg} \cdot \mathrm{L}^{-1}$ instantaneously, and if additionnally the biodegradation is high and reaches up to about $0.4 \mathrm{mg} \cdot \mathrm{L}^{-1} \mathrm{HP}$ per $\mathrm{h}$, a dose of up to $5 \mathrm{mg} \cdot \mathrm{L}^{-1} \mathrm{HP}$ may be considered for compensation. In contrast to the concentration limits we define here, based on direct water chemistry and biochemical reduction effects, Barrington et al. (2013) recommended HP addition at a fixed ratio to the presence of chlorophyll in the water which was good for realization of phytoplankton suppression but proved harmful to zooplankton (Reichwaldt et al., 2012). The effectiveness of a certain concentration of HP added to the water to selectively kill cyanobacteria depends on the residence time of HP in the water (Matthijs et al., 2012; Burson et al., 2014). A high HP decomposition rate implies a lower residence time in the water column and thus less available time for detrimental effects on the cyanobacteria, which facilitates cyanobacteria to restore vitality and this prevents their longer-term suppression. However, we judge raising of the initial HP concentration to a concentration higher than $5 \mathrm{mg} \cdot \mathrm{L}^{-1} \mathrm{HP}$ as no option: even during short exposure it will risk damage to other aquatic organisms, like zooplankton, and more than $5 \mathrm{mg} \cdot \mathrm{L}^{-1}$ measured directly after addtion is not permitted according to current local directives in The Netherlands.

High presence of anti-ROS enzymes of eukaryotic algae or the microbial community (not accounted for in this study) are most likely responsible for a high degradation rate of $\mathrm{HP}$, although cyanobacteria in high enough density may to some extent contribute to peroxide degradation as well. Some cyanobacteria produce an Extracellular Polymeric Substances (EPS) layer, which is composed of polysaccharides, proteins, lipids and fatty acids (Henderson et al., 2008; Pivokonsky et al., 2014). EPS serves as a protective buffering layer around the cell and bears antioxidant capacity to neutralize ROS like HP (Pan, 2010; Gao et al., 2015). EPS isolated from different species of bacteria, indicated even stronger antioxidant and reactive oxygen species neutralization capacity than the typical anti-oxidant vitamin C (Chowdhury et al., 2011; Ye et al., 2012). More specifically, the cyanobacterium Microcystis aeruginosa demonstrates a higher HP scavenging capacity of EPS than a similar mass of pure vitamin $\mathrm{C}$ would realize through chemical reduction (Gao et al., 2015).

In the phytoplankton concentration and dilution experiment, we mimicked the conditions experienced during a growth season in our climate zone, with low phytoplankton abundance in early spring, and higher prevalence later in the season (Sigee, 2005; Reynolds, 2006; Palleyi et al., 2011). A simple conclusion can be drawn: treatment at an early enough moment in the season is recommended. That moment can be determined quite precisely by incubating lake samples with 0 (control), 2, 3, 5, and up to $10 \mathrm{mg} \cdot \mathrm{L}^{-1} \mathrm{HP}$ in the laboratory and determining the rate of HP degradation and the decline of photosynthetic vitality of the phytoplankton. A combination should be considered of a dose that will permit minimally $2 \mathrm{mg} \cdot \mathrm{L}^{-1} \mathrm{HP}$ to be retained until $5 \mathrm{~h}$ after a treatment. If that condition is realized, the decline in photosynthetic vitality will be strong enough ( $>80 \%$ of the starting value as a realistic proxy) to avoid sudden recovery. And what if the right dose-effect response cannot be achieved with less than $5 \mathrm{mg} \cdot \mathrm{L}^{-1}$ ? For now, referring to our experience in the Western European climate zone, we advise to start earlier in the growing season when lower phytoplankton densities still limit HP degradation. The percentage loss of the photosynthetic vitality (as tested by the mini-PAM assay) depends on the contribution of cyanobacteria in the overall phytoplankton since eukaryotic algae are not much hampered by concentrations of HP below $5 \mathrm{mg} \cdot \mathrm{L}^{-1}$. A decrease of at least $80 \%$ of the photosynthetic value $5 \mathrm{~h}$ after treatment is typical for an effective treatment. This indicates a major presence of cyanobacteria in a sample, and also that HP is not broken down too rapidly as we concluded in this study from the combined assay of HP degradation and loss of photosynthetic vitality.

\section{Re-inoculation Test for Interrogation of the Sustainability of Lake Water Quality Improvement} We questioned whether after a treatment, addition of an aliquot of untreated lake water with Planktothrix would show renewed Planktothrix growth. The 7 days waiting time allowed for complete degradation of the HP. In case of renewed growth, the HP method would not be contributing to resilience; if no growth resulted, the new phytoplankton state would be such that the HP treatment method is promising in terms of sustainability. In this re-inoculation experiment, where a fresh lake sample with cyanobacterial dominance was mixed with lake samples that had been treated with different HP concentrations 7 days in advance, all freshly added cyanobacteria disappeared rapidly, except in the control samples, and no sign of a return of cyanobacteria was evidenced even after 6 weeks. This is in agreement with an earlier reported HP treatment of a Planktothrix-invaded lake: renewed growth of Planktothrix remained absent until 7 weeks after the treatment. After this period the Planktothrix abundance increased fairly rapidly again but no more than up to a level of about 200,000 cells $\cdot \mathrm{mL}^{-1}$, much lower than the 10 -fold higher cell number in a nearby control lake (Matthijs et al., 2012). Eventually, it turned out that the increase in the Planktothrix abundance seen in the whole-lake study was caused by the intake of water from an adjacent lake to compensate for water losses in the hydrologically isolated recreation lake that was treated. The water supply was necessary to correct for evaporation after a dry and warm summer period that had lowered the absolute water depth to below the required level for waterskiing. Interestingly, the new cyanobacterial inoculum in this study did not facilitate renewed growth of cyanobacteria. In other instances of whole lake treatments, the sustainability of the HP treatment was very good as well; the suppressed cyanobacteria did not return during the remainder of the growing season, and reappeared only in the next year (unpublished results). The experiments thus showed promising resilience in which added cyanobacteria found no opportunity to regain their earlier dominance, even after addition of a substantial inoculum. Explanations for the observed sustainability of the HP method are of great interest for its actual use in lake mitigation.

So-called priority-effects, i.e., the order of arrival of colonists, can have a very strong and lasting influence on a developing population and community (Drake, 1991; Beisner et al., 2003; Schröder et al., 2005). Later immigrants can have numerical 
disadvantages compared to the first colonists, which may also alter the environment in a detrimental way that severely impedes colonization success for later immigrants, especially when carrying capacity is reached before later immigrants can become abundant. In a recent study, strong effects of inoculation order have been observed for multiple-strain Microcystiscultures, with the priority effects being strain-specific (Van Gremberghe et al., 2009). These priority effects are likely to occur when cyanobacteria are inoculated in a dynamic and diverse community of green algae after HP application.

Several explanations for these priority-effects in the lake samples are plausible. Planktothrix agardhii is a species that is known to flourish under low light intensities (Mur et al., 1977). After collapse of the population, the lower plankton density may result in a higher light intensity which can hamper the growth of this species. However, the Secchi-depths in the earlier treated entire lake did not change dramatically after the treatment (Matthijs et al., 2012). Allelopathy, where green algae produce compounds that inhibit the growth of cyanobacteria, might be another explanation. In a recent study, Bittencourt-Oliveira et al. (2015) showed that the green alga Scenedesmus acuminatus significantly inhibited the growth of Microcystis aeruginosa. In our study, Scenedesmus is found together with other green algae like Desmodesmus in much larger quantities in treated samples than in the control samples (Table 1, Figures 7A,B), which could have prevented massive regrowth of surviving Planktothrix cells. However, cyanobacteria are particularly known for releasing biological compounds that have allelopathic properties as well (e.g., Leão et al., 2009), and this was indeed found in the same study where $M$. aeruginosa significantly inhibited the green alga Monoraphidium convolutum (Bittencourt-Oliveira et al., 2015). Our study similarly shows indications for allelopathic effects by Planktothrix on other phytoplankton: green algae only thrived when the cyanobacteria were first diminished (Figures 5B-F), whereas in the control samples the green algae remained low in numbers in the first 5 weeks after treatment (Figure 5A). Only when cyanobacteria became sufficiently low, other algae increased in abundance.

In this study, we did not investigate the role of and responses by the microbial community on changes in nutrient availability following a HP treatment. Although it can be argued that nutrient cycling may have been decreased due to a possible impact on the microbial community, the very fact that the green algae and diatoms grew vividly in our tests without any nutrients being added, convinced us that nutrient availability as such must have been ample. Regarding microbes in metabolic turnover, a few results from previous studies are available. Soon after a lake treatment with HP (Matthijs et al., 2012; unpublished observations), the presence of ammonium ions rose steeply, and also phosphate presence increased. From this we deduced active protease and nuclease/phosphatase activity, most likely provided by microorganisms in the lake water that resisted the HP treatment. We tested coliform numbers before and after a treatment: the number of live cells slightly increased temporarily, but then equilibrated to the pre-treatment level. After only a few days the extra ammonium was metabolized into nitrate, indicating that ammonium oxidizers are active. From this we conclude that microorganisms in the water that provide proteases, ammonium oxidizing capacity and phosphatases retain activity. As long as we are not well informed about HP effects on other prokaryotes, we consider that because microorganisms may reinoculate the water column from the sediment, a HP treatment should be carried out without affecting the sediment, by finishing HP addition at minimally $20 \mathrm{~cm}$ above the sediment. Some bacteria are also thought to play a role in scavenging HP. For example, recent experiments demonstrated that catalase-producing heterotrophic bacteria in dilute microbial communities in the surface mixed layer of the oligotrophic ocean play a vital role in protecting the cyanobacterium Prochlorococcus from oxidative damage (Morris et al., 2008, 2011). One of our current fields of study concerns impacts and consequences of HP for the microbial community, including the role of HP scavenging by heterotrophic bacteria, since a better ecological understanding is necessary for societal acceptance of the HP technique as an ecological safe cyanocide.

Another explanation for the longer term absence of cyanobacteria after a HP treatment may be the potential role of freshwater cyanophages that have been recognized to attribute to lake ecology and in termination of cyanobacterial blooms (Tucker and Pollard, 2005; Deng and Hayes, 2008; Steenhauer et al., 2014; Watkins et al., 2014). In marine surface waters, back ground values of naturally available HP can induce an enhanced viral production in bacterial communities (Weinbauer and Suttle, 1999). HP treatment-introduced peroxide may raise the vulnerability of cyanobacterial cells to new cyanophage infection, followed by a release of viruses. This would create a large enough cyanophage population in the water column to effectively control the cyanobacterial population.

\section{Phytoplankton Community Analysis by Phyto-PAM and Microscopy}

The data presented in this work introduced use of the PhytoPAM technique for coarse interrogation of the lake phytoplankton community and the acquired data were finetuned by classical microscopical analysis of the phytoplankton community. Direct comparison of microscopy data with those of the Phyto-PAM reveals a shortcoming of the Phyto-PAMassisted phytoplankton composition analysis: in one or two of the treated replicates with $2.5 ; 5$; and $10 \mathrm{mg} \cdot \mathrm{L}^{-1} \mathrm{HP}$ cyanobacteria were found by microscopy counting (Table 1) whilst the cyanobacterial fluorescence signal was only present at the lowest $\mathrm{HP}$ concentration of $2.5 \mathrm{mg} \cdot \mathrm{L}^{-1}$ and in only one of the three replicates (Figure 5B). It appears that cyanobacterial fluorescence in a mix with eukaryotic algae, gives an underestimation of the cyanobacterial abundance and an overestimation of the other algae. This is why in microscopy remaining cyanobacteria were revealed 25 days after the HP incubation that were not detected in the Phyto-PAM assay.

Moreover, as a consequence of fluorescence emitted by free phycobilisomes, the Phyto-PAM technique is not considered suitable for monitoring immediately after HP application, especially when HP dosing was high enough to cause mass lysis of phycobilisomes. Nonetheless, after a few days, especially with a low HP treatment dose, the use of the Phyto-PAM is 
recommended as a fast and easy monitoring device, to distinguish between main algal groups in a coarse way. In fact, also microscopy is not well suited for fast post-treatment analysis: the integrity of some cyanobacterial cells remains visibly unaffected until quite some time after a treatment, whereas still viable green algae often show a temporary wrinkled appearance (unpublished observations).

\section{HP Application Contributes Toward a Desirable Healthy Ecosystem State}

High diversity ecosystems are considered to have a higher resilience (Folke et al., 2004), where resilience can be defined as the capacity of a system to absorb disturbance and reorganize while undergoing change so as to retain essentially the same function, structure, identity, and feedbacks (Walker et al., 2004). Several studies on lake systems show that a loss of resilience, usually caused by human-induced eutrophication, often triggers a shift from a stable state with clear water rich in submerged vegetation, to an alternative stable state with turbid water, loss of biodiversity and high algal biomass (Scheffer et al., 1993, 1997, 2001). It is argued that once a system has turned into a turbid state, the threshold level for reduced nutrient load to cause the system to shift back to a clear state, is substantially lower than the threshold level which initially caused the system to become turbid. An important factor is that many cyanobacteria are not only excellent competitors under low light conditions; they are also capable, more than eukaryotic phytoplankton, of causing higher turbidity per unit of phosphorus and hence promote low light conditions (Scheffer et al., 1997). As a consequence, nutrient reduction is often unsuccessful (Sas, 1989; Scheffer et al., 1993), and additional measures like foodweb manipulation must be implemented to push a lake into a desired state. For example, biomanipulation experiments in a whole lake show that a strong reduction of fish biomass could act as a 'shock therapy' to turn the turbid lake back into a clear state (Meijer, 1994).

Interestingly, HP treatment when effective, causes massive killing and lysis of cyanobacterial cells resulting in temporarily increased nutrient levels. These nutrients may in turn become a food source for the remaining taxa, which are not affected by the treatment, and contribute to lake restoration with higher diversity, and food chain value. This scenario was actually displayed in our experiments, where after HP application as 'shock therapy' cyanobacterial dominance was rapidly replaced by a higher species diversity without any species dominance. If the application is accompanied by a reduction in internal and external nutrient loading, this new state with a diverse phytoplankton community might be established for the longer term and support lake mitigation. However, until now HP applications have been used in eutrophic systems where nutrient reduction is regarded not feasible or not yet effective, and the diverse phytoplankton community will fall back to a cyanobacteria-dominated ecosystem and require a renewed HP treatment in each new growth season.

\section{Concluding Remarks}

HP treatment established sustained suppression of cyanobacterial dominance in Planktothrix-dominated lake samples. The water remained perfectly suitable for phytoplankton growth; green algae and diatoms thrived. It appeared that eukaryotic phytoplankton responded favorably to the suppression of cyanobacteria and that in retrospect, the green algae gained enhanced competitiveness and restrained cyanobacteria from re-establishing in the ecosystem. This is a highly interesting observation and is focus of current follow-up research in our laboratory. Following the shock therapy with HP, which may take place with or without ongoing nutrient-load reduction measures, the fear for toxic cyanobacterial dominance in lake phytoplankton may be relieved; however, we admit that sustainable reduction of phytoplankton eventually relies on continued reversal of eutrophication in lake ecosystems. Finally, we stress that HP degrades to harmless water and oxygen, and leaves no permanent traces of the added chemical in the lake water. As such the 'HP method' appears to be a promising method on its own or serve as an accompanying measure to re-oligotrophication practice to render instant result in lake ecosystem mitigation on demand.

\section{Author Contributions}

This study was conceived and designed by HM and EW, conducted by EW and VL, while the laboratory work was supervised by HM and MS, microscopical analysis was performed by VL and MV; EW, HM, and PV wrote the manuscript. All authors declare to agree with the final manuscript and support its submission for publication.

\section{Acknowledgments}

We would like to acknowledge the Cyanocost COST action 1109 for sponsoring meetings and a training school on HP treatments which facilitated discussions that greatly stimulated the work.

\section{Supplementary Material}

The Supplementary Material for this article can be found online at: http://journal.frontiersin.org/article/10.3389/fmicb. 2015.00714

\section{References}

Ai, Y., Bi, Y. H., and Hu, Z. Y. (2015). Changes in phytoplankton communities along nutrient gradients in Lake Taihu: evidence for nutrient reduction strategies. Chin. J. Oceanol. Limn. 33, 447-457. doi: 10.1007/s00343-0154079-9

Akhurst, D., Jones, G. B., and McConchie, D. M. (2004). The application of sediment capping agents on phosphorus speciation and mobility in a sub-tropical dunal lake. Mar. Freshwat. Res. 55, 715-725. doi: 10.1071/ MF03181

Allahverdiyeva, Y., Ermakova, M., Eisenhut, M., Zhang, P., Richaud, P., Hagemann, M., et al. (2011). Interplay between flavodiiron proteins and 
photorespiration in Synechocystis sp. PCC 6803. J. Biol. Chem. 286, 24007-24014. doi: 10.1074/jbc.M111.223289

Allahverdiyeva, Y., Mustila, H., Ermakova, M., Bersanini, L., Richaud, P., Ajlani, G., et al. (2013). Flavodiiron proteins Flv1 and Flv3 enable cyanobacterial growth and photosynthesis under fluctuating light. Proc. Natl. Acad. Sci. U.S.A. 110, 4111-4116. doi: 10.1073/pnas.1221194110

Apel, K., and Hirt, H. (2004). Reactive oxygen species: metabolism, oxidative stress, and signal transduction. Annu. Rev. Plant Biol. 55, 373-399. doi: 10.1146/annurev.arplant.55.031903.141701

Asada, K. (2000). The water-water cycle as alternative photon and electron sinks. Philos. Trans. R. Soc. Lond. B Biol. Sci. 355, 1419-1431. doi: 10.1098/rstb.2000.0703

Asada, K. (2006). Production and scavenging of reactive oxygen species in chloroplasts and their functions. Plant Physiol. 141, 391-396. doi: 10.1104/pp.106.082040

Barrington, D. J., Reichwaldt, E. S., and Ghadouani, A. (2013). The use of hydrogen peroxide to remove cyanobacteria and microcystins from waste stabilization ponds and hypereutrophic systems. Ecol. Eng. 50, 86-94. doi: 10.1016/j.ecoleng.2012.04.024

Barroin, G., and Feuillade, M. (1986). Hydrogen-peroxide as a potential algicide for Oscillatoria-Rubescens Dc. Water Res. 20, 619-623. doi: 10.1016/00431354(86)90026-6

Beisner, B. E., Haydon, D. T., and Cuddington, K. (2003). Alternative stable states in ecology. Front. Ecol. Environ. 1, 376-382. doi: 10.2307/3868190

Bittencourt-Oliveira, M. D., Chia, M. A., De Oliveira, H. S. B., Araujo, M. C., Molica, R., and Dias, C. T. S. (2015). Allelopathic interactions between microcystin-producing and non-microcystin-producing cyanobacteria and green microalgae: implications for microcystins production. J. Appl. Phycol. 27, 275-284. doi: 10.1007/s10811-014-0326-2

Douglas, G. B., Robb, M. S., Coad, D. N., and Ford, P. W. (2004). “A review of solid phase adsorbents for the removal of phosphorus from natural and waste waters," in Phosphorus in Environmental Technology - Removal, Recovery, Applications, Chap. 13, ed E. Valsami-Jones (London: IWA Publishing), 291-320.

Burson, A., Matthijs, H. C. P., De Bruijne, W., Talens, R., Hoogenboom, R., Gerssen, A., et al. (2014). Termination of a toxic Alexandrium bloom with hydrogen peroxide. Harmful Algae 31, 125-135. doi: 10.1016/j.hal.2013. 10.017

Carey, C. C., Ibelings, B. W., Hoffmann, E. P., Hamilton, D. P., and Brookes, J. D. (2012). Eco-physiological adaptations that favour freshwater cyanobacteria in a changing climate. Water Res. 46, 1394-1407. doi: 10.1016/j.watres.2011.12.016

Chowdhury, S. R., Basak, R. K., Sen, R., and Adhikari, B. (2011). Optimization, dynamics, and enhanced production of a free radical scavenging extracellular polysaccharide (EPS) from hydrodynamic sediment attached Bacillus megaterium RB-05. Carbohyd. Polym. 86, 1327-1335. doi: 10.1016/j.carbpol.2011.06.050

Coesel, P. F. M., and Meesters, J. (2007). Desmids of the Lowlands. Mesotaeniaceae and Desmidiaceae of the European Lowlands. Zeist: KNNV Publishing.

Conley, D. J., Paerl, H. W., Howarth, R. W., Boesch, D. F., Seitzinger, S. P., Havens, K. E., et al. (2009). Ecology. Controlling eutrophication: nitrogen and phosphorus. Science 323, 1014-1015. doi: 10.1126/science.1167755

Deng, L., and Hayes, P. K. (2008). Evidence for cyanophages active against bloom-forming freshwater cyanobacteria. Freshwat. Biol. 53, 1240-1252. doi: 10.1111/j.1365-2427.2007.01947.x

Dodds, W. K., Bouska, W. W., Eitzmann, J. L., Pilger, T. J., Pitts, K. L., Riley, A. J., et al. (2009). Eutrophication of US freshwaters: analysis of potential economic damages. Environ. Sci. Technol. 43, 12-19. doi: 10.1021/Es801217q

Drabkova, M., Admiraal, W., and Marsalek, B. (2007a). Combined exposure to hydrogen peroxide and light-selective effects on cyanobacteria, green algae, and diatoms. Environ. Sci. Technol. 41, 309-314. doi: 10.1021/es060746i

Drabkova, M., Matthijs, H. C. P., Admiraal, W., and Marsalek, B. (2007b). Selective effects of $\mathrm{H} 2 \mathrm{O} 2$ on cyanobacterial photosynthesis. Photosynthetica 45, 363-369. doi: 10.1007/s11099-007-0062-9

Drake, J. A. (1991). Community-assembly mechanics and the structure of an experimental species ensemble. Am. Nat. 137, 1-26. doi: 10.1086/ 285143

Folke, C., Carpenter, S., Walker, B., Scheffer, M., Elmqvist, T., Gunderson, L., et al. (2004). Regime shifts, resilience, and biodiversity in ecosystem management.
Annu. Rev. Ecol. Evol. S 35, 557-581. doi: 10.1146/annurev.ecolsys.35.021103. 105711

Gao, L., Pan, X., Zhang, D., Mu, S., Lee, D. J., and Halik, U. (2015). Extracellular polymeric substances buffer against the biocidal effect of $\mathrm{H} 2 \mathrm{O} 2$ on the bloomforming cyanobacterium Microcystis aeruginosa. Water Res. 69, 51-58. doi: 10.1016/j.watres.2014.10.060

Helman, Y., Barkan, E., Eisenstadt, D., Luz, B., and Kaplan, A. (2005) Fractionation of the three stable oxygen isotopes by oxygen-producing and oxygen-consuming reactions in photosynthetic organisms. Plant Physiol. 138 2292-2298. doi: 10.1104/pp.105.063768

Helman, Y., Tchernov, D., Reinhold, L., Shibata, M., Ogawa, T., Schwarz, R., et al. (2003). Genes encoding a-type flavoproteins are essential for photoreduction of O-2 in cyanobacteria. Curr. Biol. 13, 230-235. doi: 10.1016/S09609822(03)00046-0

Henderson, R. K., Baker, A., Parsons, S. A., and Jefferson, B. (2008). Characterisation of algogenic organic matter extracted from cyanobacteria, green algae and diatoms. Water Res. 42, 3435-3445. doi: $10.1016 /$ j.watres.2007.10.032

Hillebrand, H., and Sommer, U. (2000). Diversity of benthic microalgae in response to colonization time and eutrophication. Aquat. Bot. 67, 221-236. doi: 10.1016/S0304-3770(00)00088-7

Huisman, J., Sharples, J., Stroom, J. M., Visser, P. M., Kardinaal, W. E. A., Verspagen, J. M. H., et al. (2004). Changes in turbulent mixing shift competition for light between phytoplankton species. Ecology 85, 2960-2970. doi: 10.1890/03-0763

Jancula, D., and Marsalek, B. (2011). Critical review of actually available chemical compounds for prevention and management of cyanobacterial blooms. Chemosphere 85, 1415-1422. doi: 10.1016/j.chemosphere.2011.08.036

Jin, J., and Copper, P. (2008). Response of brachiopod communities to environmental change during the Late Ordovician mass extinction interval, Anticosti Island, eastern Canada. Fossils and Strata 54, 41-51.

Krammer, K., and Lange-Bertalot, H. (1986-1991). "Bacillariophyceae," in Süßwasserflora von Mitteleuropa 2, eds H. Ettl, J. Gerloff, H. Heynig, and D. Mollenhauer (Stuttgart: Gustav Fischer Verlag), 1-4.

Krebs, C. J. (1989). Ecological Methods. New York, NY: Harper \& Row Publishers. Komárek, J., and Anagnostidis, K. (2005). Cyanoprokaryota. 2. Teil: Oscillatoriales. Süßwasserflora von Mitteleuropa 19(2). Stuttgart: Gustav Fischer Verlag.

Komárek, J., and Fott, B. (1983). "Chlorophyceae (Grünalgen). Ordnung: chlorococcales," in Das Phytoplankton des Süsswassers. Systematiek und Biologie. Die Binnengewässer. Band XVI, 7. Teil, 1. Hälfte, ed G. HuberPestalozzi (Stuttgart: E Schweizerbartsche Verlagsbuchhandlung), 1044.

Latifi, A., Ruiz, M., and Zhang, C. C. (2009). Oxidative stress in cyanobacteria. FEMS Microbiol. Rev. 33, 258-278. doi: 10.1111/j.1574-6976.2008.00134.x

Leao, P. N., Vasconcelos, M. T., and Vasconcelos, V. M. (2009). Allelopathy in freshwater cyanobacteria. Crit. Rev. Microbiol. 35, 271-282. doi: $10.3109 / 10408410902823705$

Lu, C. P., Lin, C. T., Chang, C. M., Wu, S. H., and Lo, L. C. (2011). Nitrophenylboronic acids as highly chemoselective probes to detect hydrogen peroxide in foods and agricultural products. J. Agric. Food. Chem. 59, 11403-11406. doi: 10.1021/jf202874r

Lürling, M., Meng, D., and Faassen, E. J. (2014). Effects of hydrogen peroxide and ultrasound on biomass reduction and toxin release in the cyanobacterium, Microcystis aeruginosa. Toxins 6, 3260-3280. doi: 10.3390/toxins 6123260

Lürling, M., and Van Oosterhout, F. (2013). Controlling eutrophication by combined bloom precipitation and sediment phosphorus inactivation. Water Res. 47, 6527-6537. doi: 10.1016/j.watres.2013.08.019

Matthijs, H. C., Visser, P. M., Reeze, B., Meeuse, J., Slot, P. C., Wijn, G., et al. (2012). Selective suppression of harmful cyanobacteria in an entire lake with hydrogen peroxide. Water Res. 46, 1460-1472. doi: 10.1016/j.watres.2011.11.016

Mehler, A. H. (1951). Studies on reactions of illuminated chloroplasts: I. Mechanism of the reduction of oxygen and other hill reagents. Arch. Biochem. Biophys. 33, 65-77. doi: 10.1016/0003-9861(51)90082-3

Meijer, M. L., Jeppesen, E., van Donk, E., Moss, B., Scheffer, M., Lammens, E., et al. (1994). Long-term responses to fish-stock reduction in small shallow lakes: interpretation of five-year results of four biomanipulation cases in The Netherlands and Denmark. Hydrobiologia, 275-276, 457-466. doi: $10.1007 / \mathrm{BF} 00026734$ 
Michalak, A. M., Anderson, E. J., Beletsky, D., Boland, S., Bosch, N. S., Bridgeman, T. B., et al. (2013). Record-setting algal bloom in Lake Erie caused by agricultural and meteorological trends consistent with expected future conditions. Proc. Natl. Acad. Sci. U.S.A. 110, 6448-6452. doi: $10.1073 /$ pnas. 1216006110

Morris, J. J., Johnson, Z. I., Szul, M. J., Keller, M., and Zinser, E. R. (2011). Dependence of the cyanobacterium Prochlorococcus on hydrogen peroxide scavenging microbes for growth at the ocean's surface. PLoS ONE 6:e16805. doi: 10.1371/journal.pone.0016805

Morris, J. J., Kirkegaard, R., Szul, M. J., Johnson, Z. I., and Zinser, E. R. (2008). Facilitation of robust growth of Prochlorococcus colonies and dilute liquid cultures by "helper" heterotrophic bacteria. Appl. Environ. Microb. 74, 4530-4534. doi: 10.1128/AEM.02479-07

Mur, L. R., Gons, H. J., and Vanliere, L. (1977). Some experiments on competition between green-algae and blue-green bacteria in light-limited environments. Fems Microbiol. Lett. 1, 335-338. doi: 10.1111/j.1574-6968.1977.tb00646.x

NEN-EN 15204. (2006). Water Quality - Guidance Standard on the Enumeration of Phytoplankton using Inverted Microscopy (Utermöhl Technique). Delft: Nederlands Normalisatie-Instituut.

Paerl, H. W., and Huisman, J. (2008). Climate. Blooms like it hot. Science 320, 57-58. doi: 10.1126/science. 1155398

Paerl, H. W., Xu, H., Hall, N. S., Rossignol, K. L., Joyner, A. R., Zhu, G. W., et al. (2015). Nutrient limitation dynamics examined on a multi-annual scale in Lake Taihu, China: implications for controlling eutrophication and harmful algal blooms. J. Freshwat. Ecol. 30, 5-24. doi: 10.1080/02705060.2014. 994047

Palleyi, S., Kar, R. N., and Panda, C. R. (2011). Influence of water quality on the biodiversity of phytoplankton in Dhamra river Estuary of Odisha Coast, Bay of Bengal. J. Appl. Sci. Environ. Manage. 15, 69-74. doi: 10.4314/jasem.v15i1.65678

Pan, X. (2010). Microbial extracellular polymeric substances: The ignored but crucial bio-interface affecting mobility of heavy metals in environment. Res. J. Biotechnol. 5, 3-4.

Passardi, F., Zamocky, M., Favet, J., Jakopitsch, C., Penel, C., Obinger, C., et al. (2007). Phylogenetic distribution of catalase-peroxidases: are there patches of order in chaos? Gene 397, 101-113. doi: 10.1016/j.gene.2007. 04.016

Pivokonsky, M., Safarikova, J., Baresova, M., Pivokonska, L., and Kopecka, I. (2014). A comparison of the character of algal extracellular versus cellular organic matter produced by cyanobacterium, diatom and green alga. Water Res. 51, 37-46. doi: 10.1016/j.watres.2013.12.022

Reichwaldt, E. S., Zheng, L., Barrington, D. J., and Ghadouani, A. (2012). Acute toxicological response of Daphnia and Moina to hydrogen peroxide. J. Environ. Eng. 138, 607-611. doi: 10.1061/(Asce)Ee.1943-7870.0000508

Reynolds, C. S. (2006). Ecology of Phytoplankton. Cambridge: Cambridge University Press.

Sas, H. (1989). Lake Restoration by Reduction of Nutrient Loading: Expectations, Experiences, Extrapolations. St. Augustin: Academia Verlag Richarz.

Shannon, C. E., and Weaver, W. (1949). The Mathematical Theory of Communication. Urbana, IL: University of Ilinois Press.

Scheffer, M., Carpenter, S., Foley, J. A., Folke, C., and Walker, B. (2001). Catastrophic shifts in ecosystems. Nature 413, 591-596. doi: 10.1038/35098000

Scheffer, M., Hosper, S. H., Meijer, M. L., Moss, B., and Jeppesen, E. (1993). Alternative equilibria in shallow lakes. Trends. Ecol. Evol. 8, 275-279. doi: 10.1016/0169-5347(93)90254-M

Scheffer, M., Rinaldi, S., Gragnani, A., Mur, L. R., and Vannes, E. H. (1997). On the dominance of filamentous cyanobacteria in shallow, turbid lakes. Ecology 78, 272-282.

Schreiber, U. (2004). "Pulse-amplitude-modulation (PAM) fluorometry and saturation pulse method: an overview," in Chlorophyll a Fluorescence, eds G. C. Papageorgiou and Govindjee (Dordrecht: Springer), 279-319. doi: 10.1007/978-1-4020-3218-9_11
Schröder, A., Persson, L., and De Roos, A. M. (2005). Direct experimental evidence for alternative stable states: a review. Oikos 110, 3-19. doi: 10.1111/j.00301299.2005.13962.x

Shigeoka, S., Ishikawa, T., Tamoi, M., Miyagawa, Y., Takeda, T., Yabuta, Y., et al. (2002). Regulation and function of ascorbate peroxidase isoenzymes. J. Exp. Bot. 53, 1305-1319. doi: 10.1093/jexbot/53.372.1305

Sigee, D. C. (2005). Freshwater Microbiology: Biodiversity and Dynamic Interactions of Microorganisms in the Freshwater Environment. Chichester: John Wiley \& Sons.

Steenhauer, L. M., Pollard, P. C., Brussaard, C. P. D., and Sawstrom, C. (2014). Lysogenic infection in sub-tropical freshwater cyanobacteria cultures and natural blooms. Mar. Freshwat. Res. 65, 624-632. doi: 10.1071/ Mf13094

Stumpf, R. P., Wynne, T. T., Baker, D. B., and Fahnenstiel, G. L. (2012). Interannual variability of cyanobacterial blooms in Lake Erie. PLoS ONE 7:e42444. doi: 10.1371/journal.pone.0042444

Tucker, S., and Pollard, P. (2005). Identification of cyanophage Ma-LBP and infection of the cyanobacterium Microcystis aeruginosa from an Australian subtropical lake by the virus. Appl. Environ. Microbiol. 71, 629-635. doi: 10.1128/AEM.71.2.629-635.2005

Utermöhl, H. (1958). Zur Vervollkomnung der quantitativen PhytoplanktonMethodik. Mitteilungen der Internationale Vereinigung für Theoretische und Angewandte Limnologie 9, 1-38.

Van Gremberghe, I., Vanormelingen, P., Van Der Gucht, K., Souffreau, C., Vyverman, W., and De Meester, L. (2009). Priority effects in experimental populations of the cyanobacterium Microcystis. Environ. Microbiol. 11, 2564-2573. doi: 10.1111/j.1462-2920.2009.01981.x

Verspagen, J. M., Passarge, J., Johnk, K. D., Visser, P. M., Peperzak, L., Boers, P., et al. (2006). Water management strategies against toxic Microcystis blooms in the Dutch delta. Ecol. Appl. 16, 313-327. doi: 10.1890/04-1953

Verspagen, J. M., Van De Waal, D. B., Finke, J. F., Visser, P. M., Van Donk, E., and Huisman, J. (2014). Rising CO2 levels will intensify phytoplankton blooms in eutrophic and hypertrophic lakes. PLOS ONE 9:e104325. doi: 10.1371/journal.pone.0104325

Visser, P. M., Ibelings, B. W., Vanderveer, B., Koedood, J., and Mur, L. R. (1996). Artificial mixing prevents nuisance blooms of the cyanobacterium Microcystis in Lake Nieuwe Meer, the Netherlands. Freshwat. Biol. 36, 435-450. doi: 10.1046/j.1365-2427.1996.00093.x

Walker, B., Hollin, C. S., Carpenter, S. R., and Kinzig, A. (2004). Resilience, adaptability and transformability in social-ecological systems. Ecol. Soc. 9. Available online at: http://www.ecologyandsociety.org/vol9/iss2/art5/.

Watkins, S. C., Smith, J. R., Hayes, P. K., and Watts, J. E. (2014). Characterisation of host growth after infection with a broad-range freshwater cyanopodophage. PLoS ONE 9:e87339. doi: 10.1371/journal.pone.0087339

Weinbauer, M. G., and Suttle, C. A. (1999). Lysogeny and prophage induction in coastal and offshore bacterial communities. Aquat. Microb. Ecol. 18, 217-225.

Ye, S. H., Liu, F., Wang, J. H., Wang, H., and Zhang, M. P. (2012). Antioxidant activities of an exopolysaccharide isolated and purified from marine Pseudomonas PF-6. Carbohyd. Polym. 87, 764-770. doi: 10.1016/j.carbpol.2011.08.057

Conflict of Interest Statement: The authors declare that the research was conducted in the absence of any commercial or financial relationships that could be construed as a potential conflict of interest.

Copyright (C) 2015 Weenink, Luimstra, Schuurmans, Van Herk, Visser and Matthijs. This is an open-access article distributed under the terms of the Creative Commons Attribution License (CC BY). The use, distribution or reproduction in other forums is permitted, provided the original author(s) or licensor are credited and that the original publication in this journal is cited, in accordance with accepted academic practice. No use, distribution or reproduction is permitted which does not comply with these terms. 